\title{
ESPACIALIDAD Y RELIGIOSIDAD EN TIEMPOS DE COVID-19: APUNTES PRELIMINARES DESDE LA GEOGRAFÍA DE LAS RELIGIONES
}

\author{
- FABIÁN CLAUDIO FLORES ${ }^{1}$ \\ Geógrafo. Doctor en Ciencias Sociales y Humanas de la Universidad Nacional de Luján. Profesor del Departamento \\ de Ciencias Sociales de la UNLu (Argentina). Investigador Independiente del CONICET (Argentina). Director del \\ GIEPEC (Grupo Interdisciplinario de Estudios sobre Paisaje, Espacio y Cultura) - UNLu (Argentina). E-mail para \\ contato: licfcflores@gmail.com
}

Recebido em: 14/06/2020

Aprovado em: 2008/2020

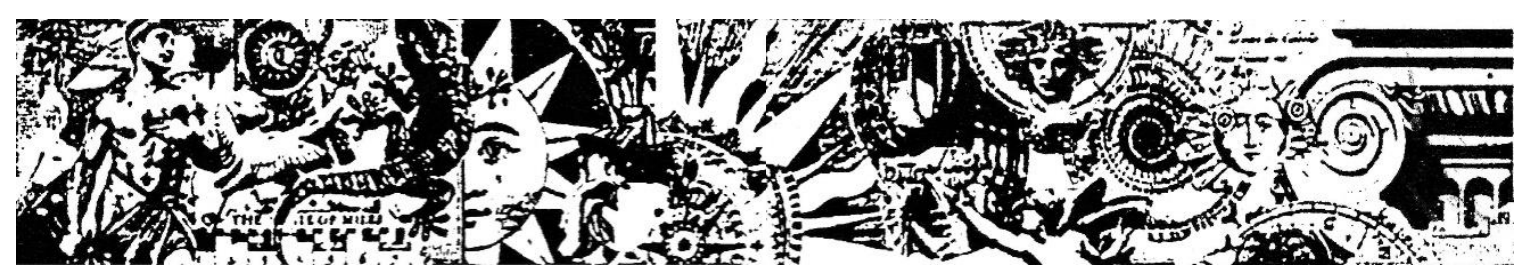

Resumen: El presente artículo examina las transfarmaciones que se generaran en las prácticas de las distintas organizaciones sacio-religiosas en el contexto de pandemia desencadenado par el avance mundial del virus CDVID-I9. Ponienda el faco en el andamiaje teórico de la geografía cultural de las religiones, se evalúa las novedasas modalidades que adquieren los procesos de sacralización de los lugares y reconfiguración de las prácticas socio-religiosas.

¿¿ué madificaciones se dan al respecto de estas espacios y sus procesos de sacralización?, ¿quú estrategias despliegan las instituciones sacio-religiosas y los fieles para continuar con las prácticas a pesar de estas restricciones?, ¿́cómo se redefine la dimensión sagrada del espacio en tiempos de encierra, distanciamiento sacial, confinamiento y virtualidad? Estos son algunos de los interrogantes que sirven como disparador para pensar de manera embrionaria todas estas transformaciones que se están gestanda y que podemos interpretarlas en el marco de la geografía de las religiones.

PALABRAS CLAVE: espacio sagrado-prácticas religiosas-CDVID-19-geografía de las religiones. 
SPATIALITY AND RELIGIOSITY IN TIMES OF CDVID-IS: PRELIMINARY NDTES FRDM THE GEQGRAPHY DF RELIIIONS

ABSTRACT: tHIS ARTICLE EXAMINES THE TRANSFDRMATIONS THAT WERE GENERATED IN THE PRACTICES OF THE DIFFERENT SOCID-RELIIIOUS ORGANIZATIINS IN THE CDNTEXT OF A PANDEMIC ACTIVATED BY THE WORLDWIDE ADVANCE OF THE CDVID-IS VIRUS. FOCUSING QN THE THEORETICAL SCAFFOLDING OF THE CULTURAL GEOGRAPHY DF RELIGIINS, THE NDVEL MDDALITIES ACDUIRED BY THE PROCESSES OF SACRALIZATION OF PLACES AND RECONFIGURATION OF SUCID-RELIGIDUS PRACTICES ARE EVALUATED. WHAT MODIFICATIONS ARE GIVEN REGARDING THESE SPACES AND THEIR PRDCESSES OF SACRALIZATION? WHAT STRATEGIES DO SOCIO-RELIGIOUS INSTITUTIONS AND THE FAITHFUL DEPLOY TO CONTINUE PRACTICES DESPITE THESE RESTRICTIINS? HOW IS THE SACRED DIMENSION DF SPACE REDEFINED? IN TIMES OF CONFINEMENT, SOCIAL DISTANCING, CONFINEMENT AND VIRTUALITY? THESE ARE SOME OF THE QUESTIONS THAT SERVE AS A TRIGGER TO THINK IN AN EMBRYGNIC WAY DF ALL THESE TRANSFORMATIINS THAT ARE TAKING PLACE AND THAT WE CAN INTERPRET WITHIN THE FRAMEWORK DF THE GEDGRAPHY OF RELIGIINS.

KEYWORDS: SACRED SPACE-RELIGIIUS PRACTICES-CDVID-IG-GEOGRAPHY DF RELIGIINS.

\section{ESPACIALIDADE E RELIGIDSIDADE NDS TEMPDS DE CDVID-IS: NOTAS PRELIMINARES DA GEOGRAFIA DAS RELILIÕES}

RESUMEN: ESTE ARTIGO EXAMINA AS TRANSFORMAÇ̃̃ES gERADAS NAS PRÁTICAS DAS DIFERENTES DRGANIZAÇ̃̃ES SÓCID

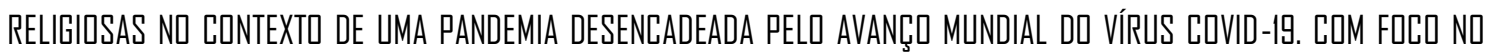
ANDAIME TÉ́RICO DA GEQGRAFIA CULTURAL DAS RELIIIÕES, SÃ̃ AVALIADAS AS NGVAS MODALIDADES ADQUIRIDAS PELIS

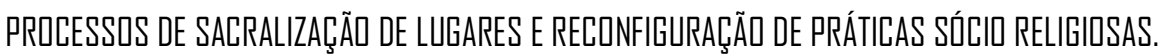

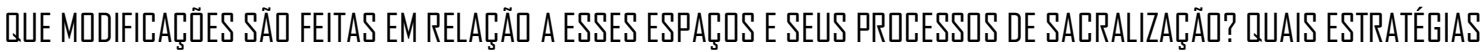
AS INSTITUIÇD̃ES E QS FIÉIS IMPLANTAM PARA CONTINUAR AS PRÁTICAS APESAR DESSAS RESTRIÇ̄ẼES? CDMUÉ REDEFINIDA A

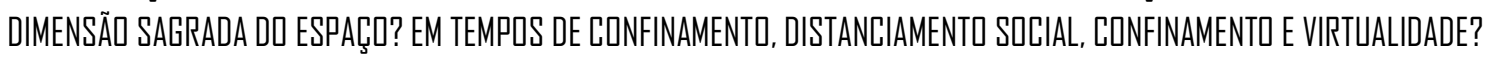
ESTAS SÃ ALGUMAS DAS PERGINTAS QUE SERVEM CDMU UM GATILHO PARA PENSAR DE MANEIRA EMBRIINÁRIA TODAS ESSAS

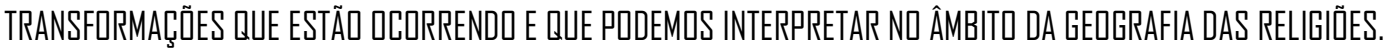
PALABRAS CLAVE: ESPAÇם SAGRADD-PRÁTICAS RELIGIOSAS-CDVID-I9-GEOGRAFIA DAS RELIIIĨES.

\section{Contexto}

El año 2020 será recordado en la historia de la Humanidad como un año atípico y extraordinario. El Mundo está experimentando una situación inusitada en mucho tiempo: una pandemia generada a partir de la difusión de una nueva variedad del virus coronavirus (COVID-19) ${ }^{1}$ provocó una serie de transformaciones en las lógicas funcionales del sistema-mundo que afectaron todos los aspectos de la vida cotidiana de personas y sociedades de cada uno de los rincones del planeta.

\footnotetext{
${ }^{1}$ El virus que emergió por primera vez en la provincia de Hubei, en el centro de China en diciembre de 2019, se expandió a través de los cinco continentes en los primeros meses del 2020, alcanzando para mediados de junio a un total de 7,5 millones infectados y 450 mil muertos. 
Nada parece escapar a los efectos de este problema de carácter global. La religión, que constituye un aspecto fundamental de gran parte de la población mundial, tampoco.

En el artículo propongo examinar, desde un enfoque geográfico, los efectos que esta situación de pandemia mundial está provocando en las prácticas religiosas en relación a espacios y lugares sagrados.

Nuevas prácticas y nuevas espacialidades se fusionan para llevar a cabo los cultos en el marco de las restricciones y legislaciones que imponen los estados al respecto de la coyuntura. ¿Qué modificaciones se dan al respecto de estos espacios y sus procesos de sacralización?, ¿qué estrategias despliegan las instituciones socio-religiosas y los fieles para continuar con las prácticas a pesar de estas restricciones?, ¿cómo se redefine la dimensión sagrada del espacio en tiempos de encierro, distanciamiento social, confinamiento y virtualidad? Estos son algunos de los interrogantes que sirven como disparador para pensar de manera embrionaria todas estas transformaciones que se están gestando y que podemos interpretarlas en el marco de la geografía de las religiones.

Finalmente, vale la pena hacer la salvedad que este artículo no pretende lograr un desarrollo exhaustivo de todas las experiencias novedosas que se están dando en el mundo en los distintos grupos o instituciones religiosas y sus prácticas; simplemente mencionar algunos ejemplos que nos sirvan como disparadores para reflexionar sobre estos procesos de reinvención y readaptación, y poner en tensión los patrones con que habitualmente entendemos la relación espacio-sacralidad desde la geografía de las religiones.

\section{Lo sagrado en tiempos de pandemia}

"When people firmly believe that a site is sacred, it's not about rationality, it's about belief systems, value systems, and emotional investment in the meaning of a space or place," (KONG, 2016, p.1). Esta afirmación de la geógrafa singapurense motiva a pensar la sacralidad de los lugares poniéndolos en relación a dos dimensiones fundamentales $y$, a la vez complementarias: lo social (y/o colectivo) y lo subjetivo (y/o individual).

Lily Kong se posiciona en el conjunto de geógrafas y geógrafos que vinieron a cuestionar algunos de los postulados nodales de la geografía de las religiones que, hasta mediados de la década de 1980, había estado fuertemente atravesada por las miradas 
morfológicas sobre los sistemas de creencias en los territorios y por la herencia eliadiana que caló hondo en la manera de concebir la dualidad de los espacios sagrados y los profanos como cualidades per se.

En el marco de la geografía cultural y otros enfoques en la misma sintonía, se recuperaron perspectivas fenomenológicas y críticas que permitieron abordar a los espacios sagrados (y profanos) de manera mucho más compleja, enfatizando en el carácter construido, dinámico y conflictivo de las hierofanías. ${ }^{2}$

Este salto conceptual es fundamental para poder pensar cómo (desde la geografía) podemos interpretar las formas contemporáneas en las que instituciones, grupos y sujetos experimentan los procesos de sacralidad en un contexto tan inusual y particular como el de una pandemia mundial en donde, entre otras cuestiones, se restringen los cultos y se cierran los ámbitos que son considerados espacios sagrados por excelencia, al menos para el caso de las religiones más institucionalizadas (iglesias, mezquitas, templos, sinagogas, shangas, gurdwaras, etcétera).

Entonces, "las manifestaciones de lo sagrado y lo secular pueden comprenderse a través de referencias culturales, experiencias y narrativas específicas. Las interpretaciones de lo sagrado nunca pueden separarse completamente de los distintos modos adquiridos de responder y expresar la sacralidad” (COOPER, 1995, p. 356) que se dan en el plano de la experiencia individual pero también en lo colectivo.

Asimismo, la producción del espacio sagrado que se lleva a cabo a través de procesos simbólicos que activan la sacralidad, suele estar franqueada por relaciones de poder que ordenan y regulan ese mundo (TUAN, 1978). Kong (1991), en la misma dirección, propone identificar dos formas básicas: una sacralidad intrínseca a partir de que en un sitio puede haber ocurrido un evento considerado extraordinario o hierofánico, y una sacralidad extrínseca, que se produce cuando, mediante la incorporación de un ritual, el espacio adquiere cierta sacralidad, y es a través de éste que alguien o algo se vuelve sagrado. En ambos casos se demandan procesos de legitimación, que no es más que la traducción de relaciones sociales de poder (FLORES, 2018). Pero a esto deberíamos sumarle una dimensión relacional que nos permita advertir en qué momento, lugar, sociedad y coyunturas se activan estos procesos, y cómo se singularizan; por ejemplo en un contexto de pandemia mundial.

\footnotetext{
2 Mircea Elíade refiere a esta categoría para mencionar a toda manifestación de lo sagrado que hace que cualquier lugar "común" se transforme en "sagrado". 
El 11 de marzo de 2020, la Organización Mundial de la Salud declaró al COVID-19 como una pandemia; esto aceleró la sanción de una serie de situaciones vinculadas con las restricciones que ya se venían tomando en gran parte de los estados del mundo. El 20 de marzo, el Estado argentino impuso el aislamiento social, preventivo y obligatorio mediante el DNU 297/2020 que, entre otras cuestiones, prohíbe la realización de eventos culturales, recreativos, deportivos, religiosos ni de ninguna otra índole que impliquen la concurrencia de personas. Esta medida se llevó a cabo en sintonía con otras tomadas en casi todos los países del mundo donde se impuso el cierre de fronteras nacionales e internacionales, la mínima circulación de personas y bienes, la exigencia del distanciamiento social y el confinamiento obligatorio, con distintas particularidades y matices.

Las actividades religiosas fueron suspendidas en (casi) todos los países, y en (casi) todas las religiones más o menos organizadas e institucionalizadas. Esto no quita que haya habido excepciones tanto dentro como fuera de las restricciones establecidas, lo que da cuenta de un panorama mucho más plural y complejo.

En líneas generales, se prohibieron las prácticas religiosas grupales, se cerraron los lugares de culto, se impidieron las procesiones, peregrinaciones y fiestas, e inclusive sitios que habitualmente son atractivos clave en el marco del turismo religioso mundial fueron cerrando progresivamente.

Estas decisiones que se tomaron a nivel de las jerarquías, (por ejemplo la Iglesia de Jesucristo de los Santos de los Últimos Días emitió un comunicado oficial para suspender las reuniones presenciales en todos sus templos del mundo) provocaron tensiones y conflictos a raíz de la consideración de algunas prácticas y algunos lugares como "esenciales" e imposibles de ser reemplazados. Tal es el caso de la necesidad de las oraciones grupales (como las reuniones del viernes de los varones musulmanes que son considerados una obligación religiosa); la generación de actividades colectivas y presenciales que garanticen la sacralidad del evento (como ha ocurrido con algunos sectores del judaísmo ultra-ortodoxo o del catolicismo ultramontano); y también la prohibición de algunas prácticas sagradas como tocar la Kaaba (incluido el cierre de la Gran Mezquita) o besar el Muro de los Lamentos, que también fue cerrado temporariamente. Inclusive se llevaron a cabo acciones vinculadas con la prevención de la pandemia que afectan - en cierto modo - la sacralidad de los lugares y generaron tiranteces en el seno de las comunidades religiosas. En el Muro de los Lamentos, sacralidad intrínseca del Judaísmo, luego de quitar todas las notas escondidas entre las ESPAÇO E CULTURA, UERJ, RJ, JUN./JUL DE 2020, N. 47, P. 37-54. http://www.e-publicacoes.uerj.br/index.php/espacoecultura/ 
grietas de las piedras (que se eliminan antes de Pésaj y se entierran en el cementerio del Monte de los Olivos con otros papeles sagrados de acuerdo con la ley judía) se procedió a desinfectar y limpiar cuidadosamente cada lugar del muro con la autorización del Rabino Shmuel Rabinowitz. Esta decisión no estuvo exenta de discusiones al interior del Judaísmo. En las mezquitas que permanecen abiertas (sobre todo en Estados Unidos) se instalaron, también, estaciones desinfectantes para higienizar las manos a medida que las personas entran y salen de estos lugares sagrados, y en el famoso monasterio de Montserrat se ha prohibido tocar y besar "la Moreneta", la Virgen patrona de Cataluña. En otros sitios, las disputas llevaron a que en los días previos a la Semana Santa no se impidan los besamanos y besapies a Vírgenes y Cristos, pero sí que se tomen recaudos limpiando la zona con un paño entre el beso de un fiel y otro.

Estas nuevas realidades han puesto en tensión la cuestión de la sacralidad/profanidad de los lugares y objetos, y obligaron a tomar medidas para alterar prácticas (algunas de ellas de mucha antigüedad y arraigo en las comunidades religiosas) que ponían en mayor riesgo de contagio a la población de fieles, a pesar de las disconformidades de algunos sectores.

¿Cómo se reconfigura lo sagrado, entonces?, ¿qué adecuaciones son necesarias para mantener el orden espacial de las prácticas religiosas mitigando la "pérdida de sacralidad"? Las respuestas son múltiples y fueron surgiendo desde las organizaciones socio-religiosas en constante negociación hacia adentro de las propias comunidades, pero también con los estados que se encargan de regular la coyuntura sanitaria. Por eso resaltamos como fundamental a todo lo expuesto, retomar la dimensión relacional para pensar los procesos de sacralidad y sacralización de los lugares concibiendo que lo sagrado no en sí mismo una propiedad inmanente sino contingente, y que se puede resignificar eventualmente. Quizás, la idea de que el espacio sagrado reside en el mundo imaginalis (KONG, 2001) puede abrimos una ventana para pensar esta realidad novedosa, "donde las fronteras de lo sagrado son trazadas por la imaginación de los seguidores, sin asociarse (necesariamente) a una territorialidad definida y localizable" (ROSENDAHL, 2009, p.46). 


\section{Distanciamiento social, virtualidad y prácticas religiosas}

La imposición del distanciamiento social y la prohibición de los cultos presenciales en muchos lugares obligaron a reconfigurar las prácticas religiosas en una nueva clave.

Frente a este panorama de orden planetario, la mayor parte de las religiones optaron por el uso de los medios y tecnologías de la información y la comunicación para continuar llevando adelante rezos, celebraciones y cultos, haciendo que los fieles participen desde sus hogares a través de estos medios. El salto a la virtualidad tuvo un impacto muy desigual tanto en las organizaciones religiosas como en sus adherentes, ya que mientras que algunas religiones y fieles contaban con el soporte necesario y la experiencia previa ${ }^{3}$ para poder entrar en la virtualidad, otros grupos tuvieron que zambullirse de lleno en un mundo poco conocido y afín, sumado a la escasez de recursos materiales y simbólicos para poder afrontar el nuevo horizonte. Por cierto, estas morfologías y sus impactos son inciertos, por lo que, siguiendo a Campbell (2016), referente de los estudios sobre religión digital, es conveniente focalizarse en cómo los patrones nuevos, importados y mejorados de "estar dentro" de espacios digitales apuntan a nuevas formas de hibridación religiosa que surgen en línea, al tiempo que hablan de los cambios en el pensamiento religioso y de los procesos que emergen dentro de la cultura "fuera de línea” (CAMPBELL, 2017).

Por un lado, la mayoría de las religiones prefirió trasladar gran parte de los rituales litúrgicos a la modalidad digital. Esto implicó la puesta en marcha de una logística y todo un soporte material que conlleva desde la habilitación de sitios específicos (las páginas web de las propias iglesias y congregaciones) hasta el uso de sitios más genéricos como las redes sociales (Facebook, Instagram, WhatsApp, etc.) o Canales de YouTube y Vimeo, y la utilización recursos para lograr la efectividad de las transmisiones (cámaras, equipos de sonido y edición, etc.), incluida la conectividad, con todo el costo económico que esta inversión implica, que no todos están en las mismas condiciones de afrontar (tanto iglesias como fieles).

\footnotetext{
${ }^{3}$ Algunas religiones tienen una amplia tradición en el uso de medios de comunicación como la radio y la televisión para oficiar sus cultos, rezos, prédicas y otras ceremonias litúrgicas; otras no se han sumado tempranamente al mundo de las religiones digitales (CAMPBELL, 2017). 
Por otro lado, el debate sobre la validez y legitimidad de este tipo de actividades digitales obligó a que cada una de las organizaciones religiosas (y sus líderes) activaran procesos de invención, resignificación y legitimación de prácticas para resolver las contingencias surgidas en el contexto del culto digital (por ejemplo, durante la Semana Santa católica se permitió el uso de otro tipo de plantas que reemplacen a los olivos que se suelen bendecir el Domingo de Ramos o la validez de la Comunión Espiritual para reemplazar a la práctica de la Eucaristía ${ }^{4}$ ). Estos nuevos rituales en línea (y los fuera de línea, también) redefinen la concepción de lo sagrado y del espacio en el que tienen marco este tipo de actividades, haciendo la salvedad desde las jerarquías religiosas que "la modalidad a distancia nunca reemplazará la experiencia comunitaria, que seguiría siendo insustituible". ${ }^{5}$ Sin embargo, algunas prácticas religiosas en modalidad virtual se han implementado rápidamente, como las misas y celebración de cultos vía Streaming, las confesiones por teléfono o Skype, como autorizó el patriarcado de Moscú de la Iglesia Ortodoxa rusa, o las procesiones, encuentros y retiros espirituales. ${ }^{6}$ En la misma dirección, las ofrendas y diezmos comenzaron a realizarse por transferencias bancarias y otros medios electrónicos.

Pero el impulso a la práctica digital excede a los rituales litúrgicos y suma fiestas, prácticas y actividades religiosas que, ante la imposibilidad de llevarlas a cabo en los lugares in situ y de manera comunitaria, encuentran su paliativo en la red. Un caso emblemático es el del «Baño virtual a Buda» mediante un sitio interactivo diseñado para tal fin (http://buddhasbirthday.fgs.org.tw/) "que permite interactuar con una figura animada del Niño Buda, arrastrando, con el mouse de la computadora un cucharón de madera para llevar a cabo el ritual [...] Como en la ceremonia offline, el procedimiento se repite tres veces mientras el Buda (mediante globos de texto) recuerda los votos de realizar buenas acciones, decir buenas palabras y tener buenos pensamientos cada vez que se vierte el agua” (CARINI, 2020, p.1). En el universo del Judaísmo mundial ya

\footnotetext{
${ }^{4}$ Para una amplia y valiosa crónica sobre las transformaciones de las prácticas católicas en Semana Santa se recomienda el artículo de Pilar García Bossio en el Blog Diversa, disponible en: http://www.diversidadreligiosa.com.ar/blog/semana-santa-y-pandemia-la-fe-vuelta-virtual/ (última consulta: mayo de 2020).

${ }^{5}$ Entrevista a Máximo Jurcinovic, Jefe de prensa de la Conferencia Episcopal de Argentina en Valores religiosos, Disponible en: https://www.valoresreligiosos.com.ar/Noticias/la-practica-de-la-fe-entreel-templo-y-el-ciberespacio-17430 (última consulta: mayo de 2020).

6 Por ejemplo, "Retiro urbano de hombres". Disponible en: https://www.facebook.com/photo/?fbid=280048280036056\&set=a.116478149726404 (última consulta: mayo de 2020) o "Entretiempo", una propuesta católica de retiros espirituales para personas de entre 35 y 60 años de la zona metropolitana de Buenos Aires. 
existía una web que incrementó geométricamente su visita: el Muro de los Lamentos virtual (https://es.thekotel.org/). Ingresando al sitio se puede enviar una plegaria, que, respetando el anonimato y la confidencialidad, será recitada por los Minyán frente al Muro sagrado situado en Israel. Esta práctica digital se complementa con otra presencial (ambas igualmente sagradas y válidas), que a la vez, debe ser regulada por la normativa del distanciamiento social y las restricciones impuestas en el sitio sagrado por las autoridades que manejan la gestión del espacio hierofánico.

En el Hinduismo, y para reemplazar la imposibilidad de realizar los viajes para contemplar a las deidades en los mandirs (práctica del darshan), se habilitaron sitios de "adoración virtual", como el que ofrece el mandir Shri Swaminarayan de BAPS (http://londonmandir.baps.org/daily-murti-darshan/); allí se puede adorar diariamente a diferentes imágenes sagradas. El ir a "dar darshan” es una de las prácticas sacras y fundamentales de los fieles del hinduismo, junto con el arti o ceremonia de la luz, que se realiza varias veces al día y que hoy se permite llevar a cabo digitalmente. En el protestantismo (en todas sus variantes) y el catolicismo se multiplicaron experiencias similares que logran resultados, por cierto, dispares. En términos de prácticas y actividades religiosas, la mayoría de los cultos ofrecen escenarios online y offline para garantizar la continuidad de las actividades.

En términos de iglesias que funcionan por Internet, Stephen Jacobs (2007) se pregunta si es posible la generación de espacios sagrados virtuales para la realización de rituales cibernéticos (JACOBS, 2007). Para poder pensar en esa dirección propone: “to understand sacred space as process and encounter, rather than simply as place or structure. This raises the possibility that different forms of encounters (e.g., specific encounters between viewer and mass-mediated event) might be regarded as instrumental in the construction of sacred space" (JACOBS, 2007, p. 1105). Desde esta perspectiva, lo sagrado se configura a partir de ese encuentro, que es un encuentro digitalmente comunitario, y que, en contexto del ritual, activa los procesos de sacralización. Esa sacralización no se impide a pesar de la ausencia física (corporal) y de que no se dé en un espacio material; aquí la hierofanía se funda a partir de esas inmaterialidades. Esta novedosa experiencia espacial, siguiendo a Qvortrup (2002) se constituye en torno a tres aspectos: la percepción del (cyber)-espacio (principalmente

\footnotetext{
${ }^{7}$ Es un número mínimo de diez varones judíos adultos (mayores de 13 años), requerido por el judaísmo ortodoxo para la realización de ciertos rituales, el cumplimiento de ciertos preceptos, o la lectura de ciertas oraciones. 


\section{6:}

una experiencia visual y auditiva); el estar en el (cyber)-espacio (movimiento) y la práctica del (cyber)-espacio (interactuar con objetos/sujetos en ese universo).

Este "salto" a la virtualidad presenta numerosas paradojas para muchos de los grupos religiosos que requieren de la presencialidad para mantener la sacralidad y legitimidad de los ritos, y si bien se han encontrado paliativos (muchos de ellos fuertemente cuestionados), no logran resolverse todas las cuestiones emergentes. En el universo de las religiones afrobrasileñas, por ejemplo, la presencia física es condición sine qua non para llevar a cabo el culto, por lo tanto en los países donde hay restricciones para las reuniones y el agrupamiento de personas no se están realizando las sesiones de umbanda, kimbanda o candomblé. "Yo como pai de santo atiendo los cuartos con las ofrendas, y ahora como se flexibilizó un poco, cuando se puede, va algún hijo o hija de la religión de la casa a ayudar; también mantenemos contacto por los grupos de Facebook y WhatsApp para pedir o agradecer"; "A" fue contundente con la imposibilidad de trasladar las sesiones al mundo digital, que requieren de una participación activa de todos los miembros. Demanda de una hierofanía extrínseca, en términos de Kong, que solo se logra en el contexto del ritual lugarizado en el templo. Así lo explicaba una practicante: "la ceremonia se tiene que hacer sí o sí dentro del templo porque tiene un montón de materialidades que le dan carácter sagrado al espacio y que son las materialidades con las cuales las entidades median sí o sí $[\ldots]$ además es necesario crear una corriente energética con las personas que participan incorporando; la energía se concentra mucho en un espacio físico y en un tiempo determinado, y las entidades llegan y son guiadas todo el tiempo; no se puede incorporar el cualquier lado". ${ }^{9}$

En el universo del Islam, las restricciones - también - afectan prácticas que demandan de la corporalidad y la afectividad como activadores de la sacralidad de los lugares; por ejemplo, se les pide a los fieles que no se abracen o se besen en la mejilla (como es práctica usual entre los varones), y que en su reemplazo se coloquen una mano sobre sus corazones haciendo un "gesto respetuoso" o una "cálida sonrisa". De manera similar, la prohibición de la reunión de los viernes (Yumu'ah) para los varones musulmanes constituyó un hecho que generó grandes tensiones en la comunidad, y si bien la mayoría de las mezquitas del mundo fueron cerradas y las reuniones vedadas,

\footnotetext{
${ }^{8}$ Entrevista al pai de santo A, del Templo Ilé Oxum Xango en Parque San Martín (Merlo, Buenos Aires, Argentina, mayo de 2020).

${ }^{9}$ Entrevista realizada a M., hija del Templo Ilé Oxum Pandá en San Miguel (Buenos Aires, Argentina, mayo de 2020). 
algunos grupos más radicales (como el salafismo) cuestionaron y violaron algunas de estas reglamentaciones. Asimismo, el Consejo de Grandes Sabios del Reino de Arabia Saudita emitió una declaración $\left(n^{\circ}\right.$ 246) que establece las "Reglas para asistir a la oración del Yumu'ah y los rezos en congregación en caso de una epidemia o temor a una epidemia”. ${ }^{10}$

Por el contrario, una de las prácticas que más resueltas tienen los musulmanes es la del salāh, los cinco rezos diarios obligatorios que deben realizarse en qibla a La Meca a lo largo del día. Este acto ritual se puede llevar a cabo en cualquier sitio (pero no en cualquier momento) porque en este caso, la sacralidad del espacio no se refiere a un lugar sagrado (más allá que la Mezquita sería la hierofanía por excelencia) sino a una topografía sagrada que se condensa por la orientación del rezo hacia la kaaba, "constituyendo una zona de sacralización personal $[\ldots]$ independiente de todo arraigamiento: deja de existir un lugar sagrado para dar paso a direcciones de lo sagrado" (MOLES y ROHMER, 1982, p. 41). ${ }^{11}$

En síntesis, el nuevo escenario digital presenta grandes desafíos para fieles y comunidades religiosas, que pone en tensión no solamente la legitimidad y santidad de las prácticas, sino que también redefine la sacralidad de los lugares.

\section{Celebrar en el encierro: ¿el espacio doméstico como nuevo espacio sagrado?}

Uno de los grandes desafíos que tuvieron que franquear las religiones más populosas fue atravesar algunas de sus principales celebraciones anuales en contexto de pandemia y encierro: el Ramadán islámico, la Pascua cristiana, el Pesajjudío y el Festival Holi del Hinduismo, entre otras. Más allá de las diferencias, estas festividades religiosas se sustentan en una fuerte dimensión colectiva que se cristaliza en el desarrollo de rituales familiares y comunitarios que se ponen en escena en distintos espacios sacralizados y escenarios geográficamente diversos. En un contexto de confinamiento y de medidas restrictivas impuestas por estados e instituciones religiosas, fiestas, rituales y celebraciones sufrieron alteraciones sustanciales. Esto trae - a priori-dos problemas

\footnotetext{
${ }^{10}$ Véase: https://www.spa.gov.sa/2047028 (última consulta: mayo de 2020).

11 "In Islam, as in Judaism, the presence of angels forms an important component in the articulation of sacred space. It is through the presence of angels that sacred places can be understood to have their sacredness authenticated, but they way in which the angels behave can also differentiate a range of sacred places into a loose "hierarchy'" (Burge, 2009, p. 244). 
centrales que están íntimamente vinculados: el de los lugares sagrados y el de las prácticas colectivas en contexto festivo. Paul Claval (2014) identifica -además- una ruptura con la vida cotidiana que es escenificada, y que crea y recrea espacialidades y temporalidades especiales (CLAVAL, 2014) que se ponen en juego durante las celebraciones. ¿Cómo se conjuga, entonces, esa ruptura de lo cotidiano, si el contexto celebratorio es el hogar (espacio cotidiano por excelencia)?

En 2020, el Ramadán se celebró entre el 23 de abril y el 23 de mayo, en varios países donde hay población musulmana muy dispar entre sí, y donde las restricciones eran de distinto tenor. Implica el ayuno obligatorio desde el amanecer al ocaso, las limitaciones en las prácticas sexuales y otras actividades vedadas moralmente, y la persistencia en la oración y recitación del Corán. Algunas de estas prácticas religiosas se desarrollan de manera individual y en sitios de sacralidad extrínseca, como hemos visto con el șalāt; sin embargo otros demandan de lugares específicos (considerados sagrados) y contextos indefectiblemente comunitarios, porque es justamente la dimensión colectiva la que legitima la hierofanía de la práctica. Por ejemplo, el iftar, que es la comida nocturna con la que se rompe el ayuno diario durante el tiempo sagrado, debe hacerse de manera grupal, respetando las regulaciones y, sustancialmente, en las mezquitas. Se trata básicamente de un evento social porque la lógica que lo articula es el compartir: tanto en las casas como en las mezquitas. Esta fiesta musulmana debió modificarse en el marco de la pandemia ${ }^{12}$, adoptando algunas singularidades que intentan mediar entre las peticiones de los fieles más conservadores y aquellos musulmanes que aceptan las reglas de aggiornamiento. "En general, las mezquitas han cerrado y no podrán acoger las plegarias colectivas. Las familias no pueden reunirse para comprar los alimentos ni cocinar los platos típicos. Tampoco se puede celebrar el final del día con amigos, en la calle, y se vuelve difícil practicar la caridad e imposible visitar personas enfermas". ${ }^{13}$ En algunos lugares, la presencialidad se reemplazó por la virtualidad: los encuentros familiares se hicieron por videollamadas y las mezquitas transmitieron en vivo sesiones de plegarias colectivas mediante redes sociales y por televisión. Desde las propias

\footnotetext{
${ }^{12}$ La OMS publicó un documento: "Prácticas seguras durante el Ramadán en el contexto de la COVID19" con recomendaciones para líderes y fieles. Disponible en: https://apps.who.int/iris/bitstream/handle/10665/331790/WHO-2019-nCoV-Ramadan-2020.1spa.pdf?sequence=1\&isAllowed=y (última consulta: mayo de 2020). 13 "El Ramadán en confinamiento". En: La Vanguardia (29/04/2020). Disponible on-line en: https://www.lavanguardia.com/vida/junior-report/20200429/48757412699/ramadanconfinamiento-coronavirus.html (última consulta: mayo de 2020). 


\section{9:}

jerarquías se desalentaron los agrupamientos, garantizando la validez del rito y de la fiesta en el nuevo escenario, e inclusive el rey saudí Salman bin Abdulaziz aprobó que haya rezos de forma limitada en la Gran Mezquita de La Meca y la del Profeta, en Medina, durante el Ramadán para evitar los contagios. Sin embargo, esta realidad muestra matices en el amplio, complejo y diverso universo del mundo musulmán. En zonas de inestabilidad política y/o donde tienen fuerte presencia los grupos más radicalizados, el horizonte es mucho más dispar con respecto al acatamiento de las medidas de confinamiento, y las celebraciones colectivas continúan llevándose a cabo como se hacían habitualmente (en algunas zonas de Siria o de Irak, por ejemplo) ${ }^{14}$.

En algunos lugares, para garantizar el carácter comunitario de la fiesta se permitió el iftar, siempre y cuando se desarrollara en las calles, en espacios abiertos y respetando la distancia social, como ocurrió en la plaza Tahrir de Bagdad (a pesar de los conflictos políticos internos, protestas sociales y la imposición del toque de queda). En las noches de Ramadán se juega mhebies, otra tradición que debió ser alterada, ya que consiste en esconder un anillo en la palma de una de las dos manos, y el jugador del equipo contrario debe adivinar en qué mano está oculto; para continuar llevando a cabo esta actividad lúdica (y sagrada) de Ramadán, se recomienda desinfectar las manos regularmente y esterilizar el anillo después de cada juego. Por su parte, en las tres noches sagradas del Laylat al Qadr (Las noches del Destino), algunos estados como Irán, reabrieron las mezquitas por un lapso de dos horas con algunas exigencias: la ocupación en su interior no debía superar el $25 \%$; en los patios o espacios abiertos se debía mantenerse la distancia social de un metro, y se le exigía que cada fiel llevara su propia alfombra para rezar, se protegiera con tapabocas y guantes en la mezquita, que -ademássería desinfectada antes y después de la ceremonia.

En el Hinduismo, entre el 9 y el 10 de marzo se celebró una de sus fiestas más importantes: el Holi o Fiesta de la primavera. Más allá del carácter sagrado, tiene una dimensión lúdica muy presente cuando los participantes se arrojan polvos de colores que tienen distintos sentidos ${ }^{15}$; este ritual se lleva a cabo en los espacios públicos y - también - privados, congregando a gran cantidad de asistentes.

\footnotetext{
${ }^{14}$ https://www.lavanguardia.com/vida/20200419/48617631007/irak-libano-y-siria-relajanrestricciones-antes-del-comienzo-mes-de-ramadan.html (última consulta: mayo de 2020). 15 Por ejemplo, el turquesa simboliza buenos augurios; el rojo refleja el amor y a la fertilidad; el azul se vincula a Krishna; los verdes refieren a las cosechas y los nuevos comienzos, y el amarillo es el color del triunfo, entre otros. 
En la edición 2020 no se prohibió su realización, ni en la India ni en Nepal, que son dos de los Estados que concentran el mayor número de adeptos; sin embargo, las autoridades (incluido el primer ministro) recomendaron que no participen y eviten las aglomeraciones. Además, el evento festivo convoca a una gran cantidad de turistas, que en esta oportunidad se vio reducida a pesar de que la pandemia se encontraba en una fase temprana.

El Holi toma cuerpo a través de distintos rituales que se llevan a cabo en tres clases de espacios jerárquicos definidos por límites territoriales y por las instituciones que operan allí (SHINDE, 2010). Así, el autor identifica: a) el espacio privado de los templos y los monasterios (ashrams); b) el espacio semipúblico y semiprivado de las relaciones de patronazgo entre funcionarios, peregrinos, devotos y visitantes que se manifiestan en rituales y performances en las instituciones religiosas; y c) el espacio público de la calle "where authority is distributed amongst religious and nonreligious institutions" (SHINDE, 2010, p. 59). Las variaciones de la fiesta parecen haber afectado con mayor intensidad a los dos primeros espacios y mucho menos al tercero (el espacio público de las calles), que igualmente tuvo un número más reducido de participantes que en las ediciones anteriores.

En la primera semana del mes de abril, dos de las religiones más numerosas celebraron una de sus fiestas anuales más importantes: la Pascua. Entre el 8 y el 16 de abril, el Judaísmo; y entre el 5 y el 11 de abril, el Cristianismo.

Habitualmente esta fiesta está atravesada por rituales celebratorios muy diversos y tradicionales que se repiten en el seno familiar y en ámbitos comunitarios como iglesias y sinagogas. En el Pesaj (Pascua judía) se celebra la liberación del pueblo hebreo de Egipto tras los años de esclavitud, mientras que en la Semana Santa, que culmina con el domingo de Pascuas, se recuerdan los últimos días de Jesucristo, su muerte y resurrección para el Cristianismo.

El contex to de pandemia y confinamiento, por supuesto, modificó gran parte de las actividades celebratorias colectivas y los rituales litúrgicos de ambos credos.

En Pesaj, el rol de las prácticas religiosas en el seno de la familia se vio alterado en gran parte de sus practicantes, aunque no en todos. El gobierno de Israel prohibió los viajes entre ciudades y las reuniones grupales e impuso toque de queda. El Seder de Pesaj, que es el ritual familiar más importante de la Pascua donde la familia se reúne a comer y celebrar, se redujo solo al grupo nuclear que habita la casa, sin visitas y con el 
uso de plataformas de transmisión para compartirlo con otros familiares. En algunos sitios de Israel se pusieron las mesas en las calles respetando la distancia social para compartir la cena con vecinos y, en otros casos, se armó el banquete en los balcones para participar con los de los alrededores. La comida y la comensalidad juegan un papel clave en la fiesta judía y sus adaptaciones no implican un cambio en los procesos de sacralidad y de reproducción de las costumbres. "Lo importante es cumplir con la verdadera tradición en la que los padres les cuentan a sus hijos las enseñanzas que recibieron de sus padres, sobre la historia de la formación del pueblo de Israel en su tránsito desde la esclavitud hacia la libertad"16. Sin embargo, dentro de la comunidad hubo tensiones y discrepancias al respecto de las mudanzas de los rituales festivos que van desde la no aceptación de las medidas restrictivas (como el caso de los grupos jaredíes en Estados Unidos y en Israel) a aquellos que aceptan parcialmente la práctica religiosa digital; sobre todo considerando que el acceso a internet, las transmisiones de televisión y ciertas funciones de los teléfonos celulares generalmente están limitadas en algunos grupos más conservadores, y en otros solo es permitido parcialmente los días previos y posteriores al Pésaj. "Si alguien desea verse por internet o participar de algún tipo de seder a través de los mecanismos de la comunicación virtual puede hacerlo en la víspera de Pésaj, antes del horario en que es prohibido usar los artefactos eléctricos". ${ }^{17}$

En el Cristianismo, las conmemoraciones de la Semana Santa y de la Pascua estuvieron marcadas -también- por el cierre de templos, iglesias y catedrales. Quizás la postal más emblemática fue cuando el Papa Francisco llevó cabo la bendición urbe et orbi en una plaza de San Pedro totalmente desierta. El traslado al mundo digital fue prácticamente una constante en todo el universo del Cristianismo para desarrollar todo el conjunto de prácticas y rituales que se exigen en la Semana Santa. Esto demandó, por un lado adaptar plataformas y mecanismos técnicos para garantizar la validez de la sacralidad en el mundo virtual, y por el otro, resignificar formas y prácticas que demandan - necesariamente - de la presencialidad y lo colectivo. Por su carácter jerárquico, la mayoría de los representantes eclesiales y fieles católicos aceptaron las nuevas reglas de juego, a pesar de que algunos sectores más conservadores se opusieron a las decisiones vaticanas de prohibir la asistencia a misa e inclusive recurrieron a la

16 Gran Rabino Sefardí Isaac Sacca, presidente de la organización judía mundial para la juventud Menorá en La Nación, 7/4/2020 (última consulta: mayo de 2020).

17 Ibídem. 
Justicia. ${ }^{18}$ Situaciones similares se vivieron en algunos evangelismos que continuaron desarrollando la práctica colectiva, aún en países que prohibían las reuniones y los cultos.

Los rituales litúrgicos también se vieron alterados, como la bendición de ramos, por ejemplo, que adquirió formas novedosas: desde la posibilidad de utilizar plantas alternativas para la bendición virtual hasta el uso de avionetas para consagraciones masivas o sacerdotes que circulaban en vehículos por las calles de los barrios bendiciendo ramos que los fieles sacaban a través de las ventanas de sus hogares.

La última cena, la adoración al Santísimo, el lavatorio, el Vía Crucis, la vigilia y la misa pascual son algunas de las prácticas religiosas que también tuvieron que buscar paliativos para desarrollarse en el ámbito de lo doméstico, individualmente o con un número reducido de personas y sin la figura de las materialidades y presencialidades que median en la "nueva normalidad" del confinamiento. Como menciona Pilar García Bossio en su crónica: "La materialidad de lo religioso se ve impedida, y el aura que rodea a lo sacro se mediatiza por una pantalla". ${ }^{19}$

Estos y otros ejemplos de fiestas religiosas nos desafían a pensar en las nuevas formas que adquieren los procesos de sacralización del espacio en contextos de encierro, y en cómo la casa se convierte en el nuevo escenario religioso (es templo, mezquita, sinagoga, sangha, etcétera) donde se activa la sacralidad mediada por las tecnologías. Además, para pensar estas neo sacralidades hogareñas es fundamental situarse en las estrategias de las instituciones socio-religiosas así como en las prácticas y las experiencias de los fieles, para ver de qué modo ambas se interceptan, combinan, hibridan y vinculan en el nuevo templo del encierro: la casa.

\section{Para seguir pensando}

Estas son apenas algunas reflexiones inaugurales que intentan poner en evidencia la cuestión de los espacios y lugares sagrados, así como las prácticas religiosas de los actores, en un contexto excepcional generado a partir de la pandemia del COVID19.

\footnotetext{
${ }^{18}$ El 3 de abril de 2020, un grupo de laicos católicos, presentó un recurso de amparo contra el Estado Nacional a fin de poder acceder a los sacramentos, que estaban impedidos por el decreto de necesidad y urgencia del gobierno argentino.

19 http://www.diversidadreligiosa.com.ar/blog/semana-santa-y-pandemia-la-fe-vuelta-virtual/ (última consulta: mayo de 2020). 
La realidad es muy compleja y heterogénea, y afecta directa e indirectamente a miles de millones de personas en todo el mundo.

Las medidas restrictivas para reuniones y agrupamientos, el cierre de los lugares para el culto, la exigencia del distanciamiento social y el confinamiento han determinado un horizonte muy incierto para las organizaciones socio-religiosos. Ante este panorama, las estrategias han sido múltiples y sus resultados dispares, como hemos pasado revista. En todos los casos, estas nuevas modalidades de lo religioso no han estado exentas de tensiones y conflictos, tanto hacia el interior de las comunidades religiosas como hacia afuera de las mismas.

Desde la geografía de las religiones emergen una serie de interrogantes y desafíos que ponen en jaque las formas convencionales en las que entendíamos la dimensión sagrada del espacio, la producción de los espacios religiosos y el vínculo sagrado/profano a partir de las prácticas socio-espaciales.

Quizás esta nueva realidad pueda ser un punto de inflexión -también- para que, desde esta perspectiva, ampliemos nuestra imaginación geográfica y comencemos a abordar cuestiones que poco (o nada) han sido evaluadas hasta el momento. Para ello sería fundamental romper con los marcos impuestos, y focalizarnos en aquellas situaciones que vuelven permeable lo público con lo privado con respecto a la emergencia de sacralidades y profanidades del espacio. Retomando las ideas pioneras de Kong (1991): "Geographers of religion have been caught up overwhelmingly, though not exclusively, with formalized systems of religions, particularly institutionalized, canonical religions of the text $[\ldots]$ There is no doubt that insufficient attention has been paid to $[\ldots]$ the personal religious experience" (p. 367).

Este contexto mundial constituye un laboratorio fructífero para pensar y repensar este tipo de experiencias espaciales novedosas y de reconfiguraciones de formas y sentidos del espacio sagrado. Situar la mirada en y desde los lugares puede ser la clave para seguir problematizando las relaciones espacio y religión en sus distintas vertientes y formas. Probablemente como sugiere Holloway (2006): "the affectual relations and forms of embodiment that produce and are produced in religious-spiritual space must be given greater attention if we are to develop more complex and nuanced analyses" (p. $186)$. 


\section{REFERENCIAS BIBLIOGRÁFICAS}

BURGE, Stephen. "Angels, Ritual and Sacred Space in Islam”. In: Comparative Islamic studies, vol.5, nro.2, 2009, p. 221-245.

CAMPBELL, Heidi. "Surveying theoretical approaches within digital religion studies". In: New Media $\Xi^{2}$ Society, 19(1): 15-24, 2017.

CARINI, Catón. "El Vesak en Argentina: del Barrio Chino a la celebración virtual en tiempos de coronavirus" en Buddhistdoor en Español, Buenos Aires, 2020.

CLAVAL, Paul. "A festa religiosa”. Em: Ateliê Geográfico, vol. 8, n.1, 2014, p. 6-29.

COOPER, Adrian. "Adolescent dilemmas of landscape, place and religious experience in a Suffolk Parish". In: Environment and Planning D: Society and Space, vol. 13, 1995, p. 349-363.

FLORES, Fabián. "Lo religioso y el espacio. Apuntes desde la Geografía" en CLOCLET DA SILVA, Ana y DI STEFANO, Roberto, História das Religiões: dimensões epistemológicas e teóricometodológicas, Rio de Janeiro: Prismas, 2018.

HOLLOWAY, Julian. "Enchanted Spaces: The Séance, Affect, and Geographies of Religion”. In: Annals of the Association of American Geographers, vol. 96, $\mathrm{n}^{\circ}$ 1, 2006, p. 182-187.

JACOBS. "Virtually Sacred: The Performance of Asynchronous Cyber - Rituals in Online Spaces". In: Journal of Computer - Mediated Communication, vol. 12, n 3, 2007, p. 1103-1121.

KONG, Lily. "Balancing The Sacred And The Secular", Asian Scientist, 20/8/2016.

KONG, Lily. "Mapping 'New' Geographies of Religion: Politics and Poetics in Modernity”. In: Progress in Human Geography, vol. 25, n. 2, 2001, p. 211-233.

KONG, Lily. "The Sacred and the Secular: Exploring Contemporary Meanings and Values for Religious Buildings in Singapore”. In: Southeast Asian Journal of Social Science, vol. 20, nro.1, 1991, p. 18-42.

MOLES, Abraham; ROHMER, Elisabeth. Labyrinthes du Vécu. L'Espace: matière d'actions, Paris: Librairie des Méridiens, 1982.

QVORTRUP, Lars. "El ciberespacio como representación de la experiencia espacial: en defensa de un enfoque fenomenológico". En: QVOTRUP, Lars (Ed.), Espacio virtual: espacialidad en mundos virtuales $3 \mathrm{D}$ habitados, Londres: Saltador, 2002, p. 5-24.

ROSENDAHL, Zeny. "Hierópolis y procesiones: lo sagrado y el espacio" en CARBALLO, Cristina (Coord.), Cultura, territorios y prácticas religiosas, Buenos Aires: Prometeo, 2009, p. 4356.

SHINDE, Kiran. "Managing Hindu Festivals in Pilgrimages sites: emerging trends, opportunities and challenges". In: Event Management, vol. 14, 2010, p. 53-67.

TUAN Yi Fu. “Sacred Space. Exploration of an Idea”. In: BUTZER, Karl (Org.), Dimension of Human Geography, Chicago: Departament of Geography/University of Chicago, 1978. 